\title{
Soil microbial biomass carbon and carbon dioxide response by glucose-C addition in black soil of China
}

\author{
Memon Muhammad Suleman ${ }^{1,2}$, Xu Hu${ }^{1}$, Zhang Wenju ${ }^{1}$, Depar Nizamuddin ${ }^{3}$ and Xu Minggang ${ }^{1}$ \\ ${ }^{1}$ National Engineering Laboratory for Improving Quality of Arable Land, Institute of Agricultural Resources and Regional \\ Planning, Chinese Academy of Agricultural Sciences, Beijing, China \\ ${ }^{2}$ Agriculture Chemistry (S.F) Section, Agriculture Research Institute, Tandojam, Sindh, Pakistan \\ ${ }^{3}$ Soil \& Environ. Sci. Div., Nuclear Institute of Agriculture, Tandojam, Sindh, Pakistan
}

\begin{abstract}
The soil microbial biomass, atmospheric carbon dioxide and abundance of decomposer are influenced by rate and addition pattern of glucose carbon. The present study was conducted to evaluate the effect of single and repeated additions of glucose-C on soil microbial biomass carbon (SMBC) and $\mathrm{CO}_{2}$ response in black soil of China. The incubator study comprising of 116-days was conducted in different fertility levels of black soil of Jilin province of China, to determine the effects of glucose addition patterns viz single addition (2\% glucose-C once application) and repeated addition (2\% glucose-C in five splits) on soil microbial biomass carbon and $\mathrm{CO}_{2}$ accumulation. Fortygram air dried soil was filled into $250 \mathrm{ml}$ Schott bottle and bottles were arranged in CRD-factorial design with 5 repeats. Factor (A), included glucose addition patterns (single \& repeated additions). Factor (B), consisted of soil fertility levels: low, medium and high on the basis of soil organic carbon. Thereafter glucose-C (2\%) solution was added drop wise to soil. The addition patterns showed positive response on $\mathrm{SMBC}, \mathrm{CO}_{2}$ evolved and $\mathrm{CO}_{2}$ accumulation. Over all mean (low, medium and high fertility soils) of repeated addition depicted $32 \%$ and $0.92 \%$ higher values of SMBC than control and single additions, respectively. The $\mathrm{CO}_{2}$ emission of repeated addition was $21.3 \%$ higher in low fertility soil. The mean $\mathrm{CO}_{2}$ accumulation showed higher values in low fertility soil by single addition than repeated and control in all soils. Single glucose-C addition in combination with different soil fertility levels augmented the microbial biomass and triggered carbon mineralization for shorter period (up to 3 weeks). The repeated addition of glucose in combination with different soil fertility levels also enhanced soil microbial biomass carbon and $\mathrm{CO}_{2}$ in longer incubation period. It is concluded from this study that microbial starvation for organic carbon was very high hence; repeated addition may be suggested to meet $C$ demand of microbes.
\end{abstract}

Keywords: Microbial biomass carbon, $\mathrm{CO}_{2}$, glucose, single addition, repeated addition

\section{Introduction}

Soil organic matter (SOM) is chief constituent of $\mathrm{C}$ and nutrient cycling; it is also major carbon reservoir of the biosphere atmosphere system (Falkowski et al., 2000). Soil organic $\mathrm{C}$ is a leading factor in many microbial processes such as soil respiration and mineralization, but both the processes are dependent on quality and quantity of $\mathrm{C}$, because it contains energy for enzyme production (Kuzyakov et al., 2000). Single addition is the application of glucose or fresh organic material (straw), farmyard manure at initial time or at the beginning of experiment. Repeated addition is the application of organic substrates per week, fortnightly, monthly throughout the experimental duration, the same amount of substrate is applied to each treatment over study period.

Organic material net mineralization-immobilization patterns in soil are affected by environmental factors
(Saccone et al., 2013) the nature and abundance of the microbes/decomposers (Kristiansen et al., 2004) and chemical composition of organic substrates (Thomas and asakawa, 1993). Microorganisms satisfy their nutrient demand with low $\mathrm{C}: \mathrm{N}$ ratio organic amendment, because microbes have low C:N ratio $(<20)$ and result the early net mineralization. In contrast, organic-C input with high C:N ratio temporarily decrease net mineralization of microbial biomass (Moritsuka et al., 2004). Decomposition rate of organic material/substrates is affected by nature of organic $\mathrm{C}$. Glucose-c or water-soluble organic C is rapidly decomposed, because it is mostly in the form of simple compounds and readily accessible to soil microbes. Degradation and decomposition of complex organic carbon requires the production of extracellular enzymes that can only be prepared by subset of microbes (Nannipieri et al., 2012).

Soil microbes influence the availability of nutrients, when organic substrate is added to soil (Gichangi et al., 2009

\footnotetext{
*Email: memonmuhammadsuleman@caas.cn
} 
and Khan 2009). Higher the microbial biomass more macronutrients (N \& $\mathrm{P}$ ) are taken up by microbes, when, organic-C availability is high. In these conditions' microbes compete with plant for nutrients. Simultaneously P fixation in clay colloids or leaching is limited due $\mathrm{P}$ uptake by microbes (Gichangi et al., 2009 \& Khan 2009). On, the contrary soil microbial biomass nitrogen (SMBN) and $\mathrm{P}$ become readily available to plant as microbial biomass turns over, when easily available carbon depletes (Gichangiet al., 2009; Malik et al., 2012). So, the microbes can be deliberated as slow release fertilizers that store nutrients particularly $\mathrm{N}$ and $\mathrm{P}$, when concentration of these nutrients is high and then release them (Ryazanova et al., 2009; Docampo et al., 2010). Therefore, for better understanding of nutrient management, it is essential to study nutrient dynamics in response to organic amendment or organic-C input and relationship between nutrient uptake by plants and soil microbial biomass. Keeping in view, this present study was designed to evaluate the effect of single and repeated additions of glucose-C on soil microbial biomass carbon (SMBC) and $\mathrm{CO}_{2}$ response in black soil of China.

\section{Materials and Methods}

\section{Soils}

Soil properties such as soil organic carbon (SOC), total $\mathrm{N}$, total $\mathrm{P}$ and total $\mathrm{K}$ of top $20 \mathrm{~cm}$ layer were $18.6 \mathrm{~g} \mathrm{~kg}^{-1}$, $2.1 \mathrm{~g} \mathrm{~kg}^{-1}, 1.46 \mathrm{~g} \mathrm{~kg}^{-1}$ and $25.3 \mathrm{~g} \mathrm{~kg}^{-1}$, respectively. Alkali hydrolysable $\mathrm{N}$, Olsen-P and $1 \mathrm{M}$, ammonium acetate was 112,29 and $186 \mu \mathrm{g} \mathrm{g}^{-1}$. Soil clay content was $28.8 \%$ (<2 $\mu \mathrm{m})$ with $\mathrm{pH}$ of 7.5 . Soil used in this incubation study was collected from top $20 \mathrm{~cm}$ from Jilin province of China. Before using the soil samples for incubation study, the sample was air dried, homogenized and sieved through 2 $\mathrm{mm}$ sieve. The stones, roots and other materials were removed from soil. The black soil having characteristics clay content $(<2 \mu \mathrm{m}) 28.8 \%$, pH ranged from 6.8 to 7.5 , water holding capacity (WHC) 59.2 to $61.8 \%$ and maintained at $60 \%$ throughout the experiment. Soil organic carbon varied from 16.25 to $31.32 \mathrm{~g} \mathrm{~kg}^{-1}$ and total nitrogen varied from 1.46 to $2.82 \mathrm{~g} \mathrm{~kg}^{-1}$ (Table 1).

\section{Experimental design}

A pot study in incubators was conducted by using CRD-factorial design with 5 repeats. Factor (A), included glucose addition patterns like control, single and repeated additions. Single addition received all amount of glucose-C at the start of experiment just after one week of incubation, repeated addition received same amount of glucose (as in single addition) in five splits and all subsequent weekly addition was with water only while control received water every week. Factor (B), consisting of soil fertility levels: low, medium and high fertility, was selected to observe response of glucose addition. The sterilized soil was used in control treatment to check microbial contamination.

Forty-gram (40 g) air dried, $2 \mathrm{~mm}$ sieved, homogenized soil was filled into $250 \mathrm{~mL}$ Schott bottle. The soil water holding capacity was maintained $60 \%$ with distilled water. The soil filled Schott bottles used in incubation were preincubated in dark at $20{ }^{\circ} \mathrm{C}$ for a week. Then $1 \mathrm{~mL}$ of glucose-C (2\%) solution or $1 \mathrm{~mL}$ water was added to soil

Table 1: Soil properties of different nutrient levels of black soil (Means $\pm S E, n=3$ )

\begin{tabular}{lllll}
\hline Soil & WHC $(\boldsymbol{\%})$ & $\mathbf{p H}$ & $\mathbf{S O C}\left(\mathbf{g ~ k g}^{-1}\right)$ & Total N $\left(\mathbf{g ~ k g}^{-1}\right)$ \\
\hline Low fertile soil & $59.2 \pm 0.029$ & $7.29 \pm 0.012$ & $16.2 \pm 0.015$ & $1.468 \pm 0.028$ \\
Medium fertile soil & $58.5 \pm 0.053$ & $7.31 \pm 0.016$ & $26.5 \pm 0.007$ & $2.316 \pm 0.031$ \\
High fertile soil & $61.8 \pm 0.042$ & $6.85 \pm 0.37$ & $31.3 \pm 0.018$ & $2.825 \pm 0.025$ \\
\hline
\end{tabular}

Table 2: F-values from analysis of variance of parameters as influenced by different glucose additions in black soil

\begin{tabular}{|c|c|c|c|c|}
\hline Parameter & $\begin{array}{l}\text { Fertility } \\
\text { Status }\end{array}$ & $\begin{array}{l}\text { Addition pattern } \\
\text { (A) }\end{array}$ & $\begin{array}{l}\text { Time in weeks } \\
\text { (T) }\end{array}$ & $\begin{array}{l}\text { Addition } \\
\text { pattern } \times \text { Time }\end{array}$ \\
\hline \multirow{3}{*}{ Microbial Biomass Carbon (mg/g C) } & Low fertility soil & $29.59 * *$ & $34.11 * *$ & $2.34 * *$ \\
\hline & Medium fertility soil & $15.7 * *$ & $97.65^{* *}$ & $3.66 * *$ \\
\hline & High fertility soil & $77.16^{* *}$ & $34.85^{* *}$ & $10.66^{* * *}$ \\
\hline \multirow{3}{*}{$\mathrm{CO}_{2}$ evolved rate $(\mathrm{mg} / \mathrm{g} \mathrm{C})$} & Low fertility soil & $566.7 * *$ & $292.3^{* * *}$ & $173.5^{* * *}$ \\
\hline & Medium fertility soil & $465.56 * *$ & $213.86^{* *}$ & $166.24 * *$ \\
\hline & High fertility soil & $519.9 * *$ & $270.4^{* *}$ & $271.5 * *$ \\
\hline \multirow{3}{*}{$\mathrm{CO}_{2}$ accumulation rate $(\mathrm{mg} / \mathrm{g} \mathrm{C})$} & Low fertility soil & $18241.6^{* * *}$ & $4618.1 * *$ & $273.3 * *$ \\
\hline & Medium fertility soil & $11966.2 * *$ & $4107.4 * *$ & $271.3^{* *}$ \\
\hline & High fertility soil & $14714.2 * *$ & $4413.9 * *$ & $399.0^{* * *}$ \\
\hline
\end{tabular}

Note: $*=$ significant, $* *=$ highly significant and $* * *=$ very highly significant at $p<0.05$ (High fertility soil showed more $\mathrm{CO}_{2}$ than added glucose-C because high fertility soil already contained soil organic-C). 
drop wise by using the pipette to obtain equal distribution in each Schott bottle. Five milliliters of $1 M$ sodium hydroxide was kept in bottles to capture $\mathrm{CO}_{2}$ and exchanged of every week. The $\mathrm{CO}_{2}$ captured samples were analysed every week. One gram of calcium chloride was placed in incubation bottle to absorb water vapor and avoid soil moisture from subsequent water additions.

\section{Analysis of soil microbial biomass carbon}

After incubation, the chloroform fumigation/extraction method modified by Vance et al., (1987) was used for quantification of SMBC. About $12.5 \mathrm{~g}$ of fresh soil was fumigated with ethanol chloroform for 24 hours, additional $12.5 \mathrm{~g}$ soil was kept un-fumigated for 24 hours and then extracted with $50 \mathrm{~mL}$ of $0.5 \mathrm{~mol} / \mathrm{L} \mathrm{K}_{2} \mathrm{SO}_{4}$, the total concentration in $\mathrm{K}_{2} \mathrm{SO}_{4}$ extracted in fumigated - nonfumigated soils. Soil microbial biomass carbon was analyzed after every three weeks throughout the experiment, week 3, 6, 9, 12 and 15, respectively. The SMBC were determined by Analytic jena Multi N/C 3100 (TOC/TN).

\section{Analysis of $\mathrm{CO}_{2}$}

Carbon dioxide $\left(\mathrm{CO}_{2}\right)$ was measured as precipitate carbonate absorbed in $\mathrm{NaOH}$. The $\mathrm{NaOH}$ was kept in bottles to trap $\mathrm{CO}_{2}$ and replaced every week. Carbon dioxide-C of samples was captured in incubation bottle and quantified for $\mathrm{CO}_{2}$, after every week. The $\mathrm{CO}_{2}$ concentrations were analyzed by Analytic jena Multi N/C 3100 while change its mode on $\mathrm{IC}, \mathrm{CO}_{2}$ evolved rate $(\mathrm{mg} / \mathrm{g} \mathrm{C})$ were calculated per week.

\section{Statistical analysis}

Every treatment contained five replicates. The data of $\mathrm{SMBC}$ and $\mathrm{CO}_{2}$ evolved and $\mathrm{CO}_{2}$ accumulation at the end of the experiment was analyzed by three-way ANOVA (analysis of variance) with glucose- $\mathrm{C}$ addition patterns (control, single and repeated additions), fertility levels (low, medium and high) and time (weeks) as (glucose additions $\times$ fertility levels $x$ weeks). Tukey HSD test was applied to assess significant difference among the treatments by using software Statistix ${ }^{\circledR}$ Version 8.1. The data were plotted using non-metric multi-dimensional scaling (MDS) plot. Significant differences in soil microbial biomass carbon, $\mathrm{CO}_{2}$ evolved and $\mathrm{CO}_{2}$ accumulation among the treatments were determined at probability HSD $(\leq 0.05)$.

\section{Results}

Soil microbial biomass carbon (SMBC), as $\mathrm{CO}_{2}$ evolved, and $\mathrm{CO}_{2}$ accumulation showed highly significant $\mathrm{F}$ values ( $p=0.000$ ) from the ANOVA (analysis of variance) for the soils, glucose addition patterns and time in weeks, respectively (Table-2). The interaction between soils $x$ addition patterns, soils $\times$ time, addition pattern $\times$ time and soils $\times$ addition pattern $\times$ time in table -2 , were also varied with highly significant F-values $(\mathrm{p}=0.000)$.

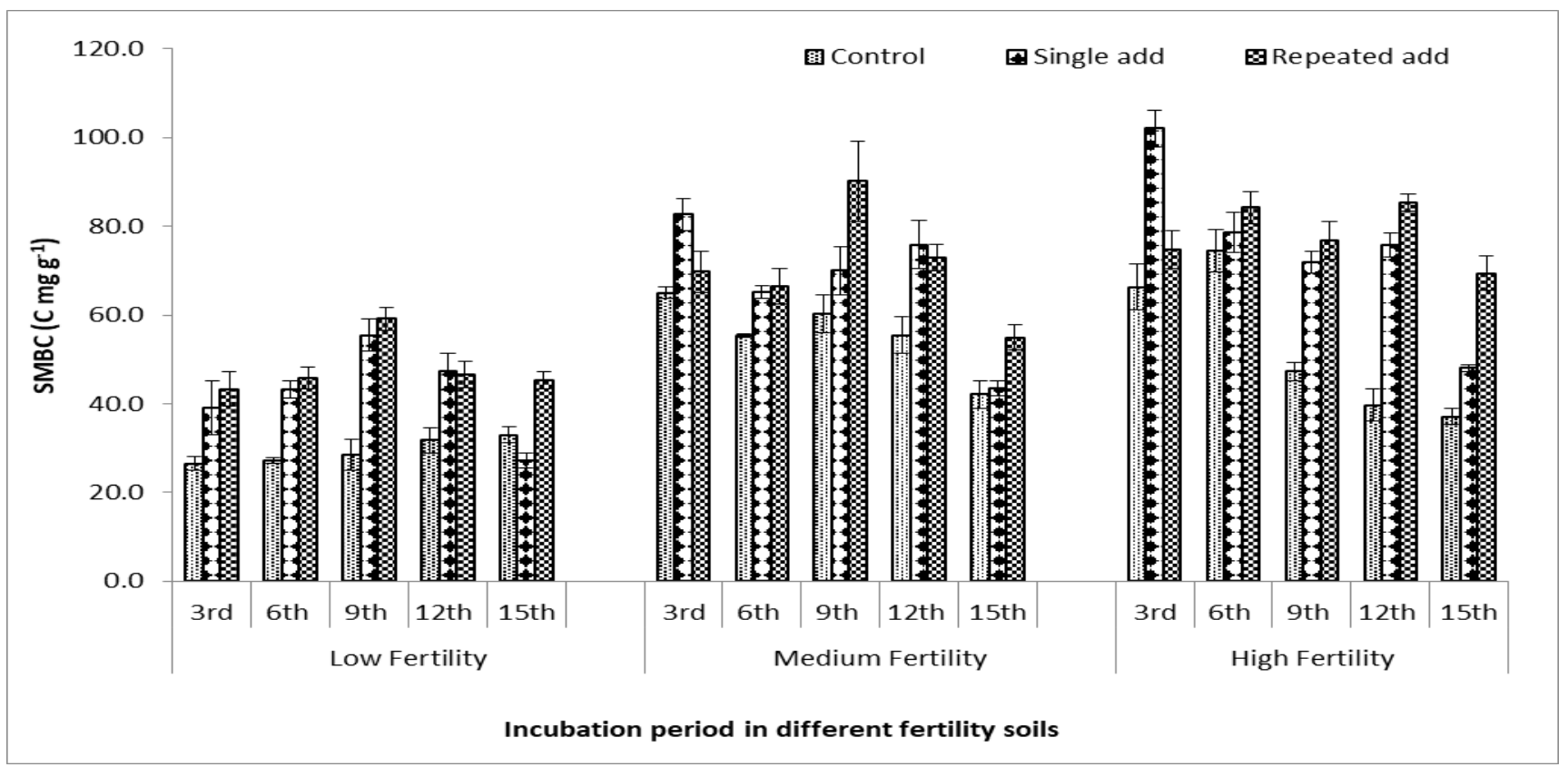

Tukey HSD $\leq$ 0.05: Low fertility (Glucose add: 3.99, Weeks:6.05, Glucose add x weeks: 13.22): Medium fertility (Glucose add: 6.09, Weeks:9.20, Glucose add x weeks: 20.12): High fertility (Glucose add:5.38, Weeks:8.15, Glucose add x weeks: 17.82).

Figure 1: Soil microbial biomass carbon with different glucose-C additions in amended black soils 


\section{Change in soil microbial biomass carbon (SMBC) by glucose addition patterns}

The glucose-C additions (single \& repeated additions) showed variable impact on SMBC. Single addition in $3^{\text {rd }}$ week showed the highest SMBC $\left(102.5 \mathrm{mg} \mathrm{g}^{-1}\right)$ in high fertility soil, followed by repeated addition in $9^{\text {th }}$ week $(90.1$ $\mathrm{mg} \mathrm{\textrm {g } ^ { - 1 }}$ ) in medium fertility soil (Figure 1). Repeated addition showed the highest (45.69 $\mathrm{mg} \mathrm{g}^{-1}$ ) SMBC during the $3^{\text {rd }}$ week of incubation period. Over all mean (low, medium and high fertility soils) of repeated addition depicted $32 \%$ and $0.92 \%$ higher values of SMBC than control and single additions, respectively (Figure $3 \mathrm{a}$ ). The incubation period of study illustrated variable impact on SMBC. Maximum SMBC (53. $94 \mathrm{mg} \mathrm{g}^{-1}$ ) was observed during the $3^{\text {rd }}$ week of incubation period. The interactive effect of glucose-C additions $\times$ weeks depicted $1179 \%$ higher SMBC by repeated addition in $3^{\text {rd }}$ week than control during $5^{\text {th }}$ week of incubation period.

\section{Change in soil carbon dioxide $\left(\mathrm{CO}_{2}\right)$ emission by glucose addition patterns}

The single glucose-C addition released the maximum $\mathrm{CO}_{2}\left(20.9 \mathrm{mg} \mathrm{g}^{-1} \mathrm{C}\right.$ soil week $\left.^{-1}\right)$ in low fertility soil during $2^{\text {nd }}$ week (Figure 2). The average $\mathrm{CO}_{2}$ emission of single addition in all amended soils was $642 \%$ and $280 \%$
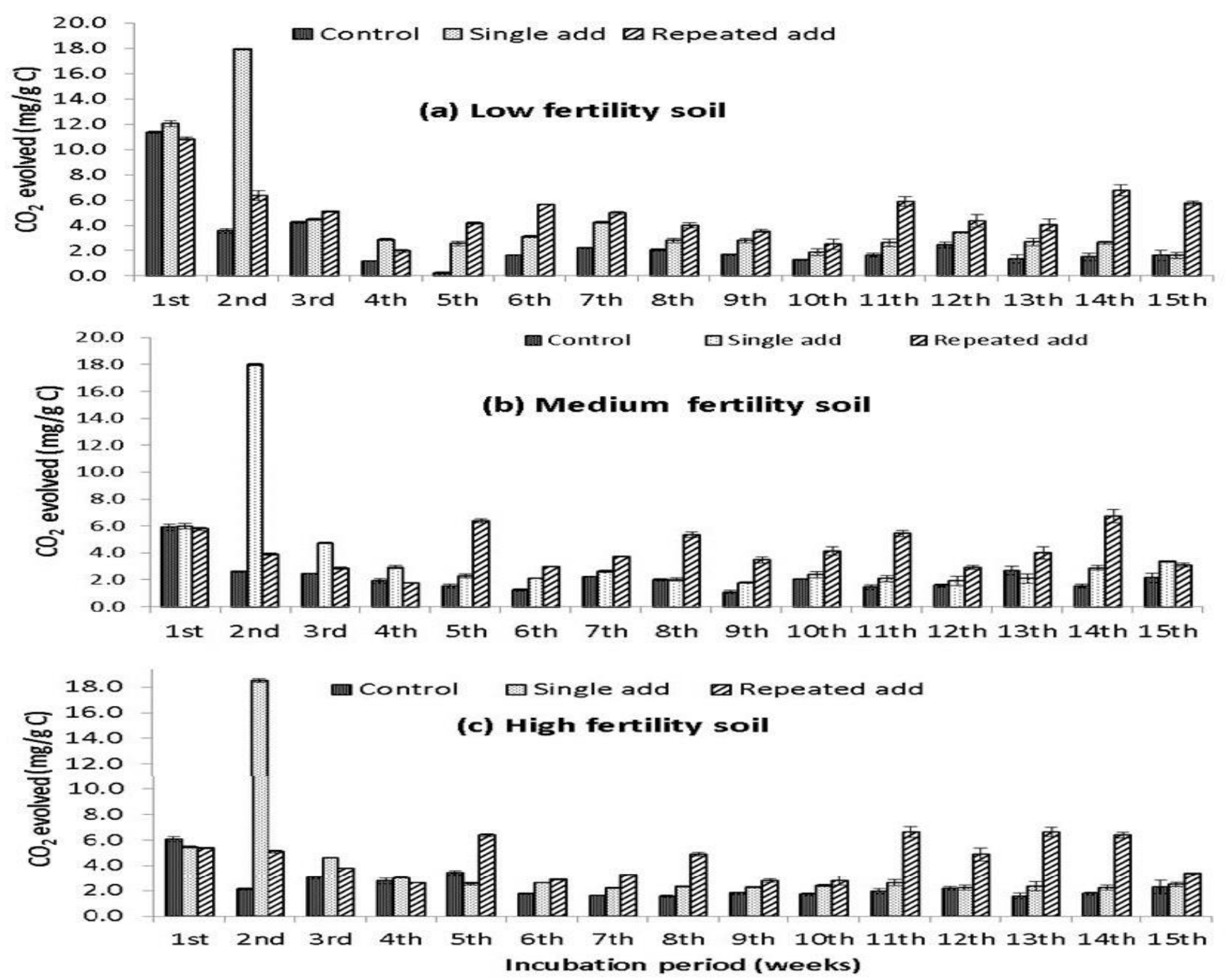

Tukey HSD $\leq 0.05$ : Low fertility (Glucose add: 0.183, Weeks:0.594, Glucose add x weeks: 1.194$)$ : Medium fertility (Glucose add: 0.16 , Weeks:0.53, Glucose add x weeks: 1.068): High fertility (Glucose add:0.147, Weeks:0.476, Glucose add x weeks: 0.958).

Figure 2: Total $\mathrm{CO}_{2}$ release from black soil with different glucose-C additions at various interval periods 
higher than control and repeated addition during $2^{\text {nd }}$ week (Figure 2).

The repeated addition released higher $\mathrm{CO}_{2}$ than single addition with consistency during the rest of all weeks. Therefore, mean wise repeated addition released more $\mathrm{CO}_{2}$ as compared to single addition and control (Figure $3 b$ ). The interactive effects amended soils and glucose-C additions showed variable response to $\mathrm{CO}_{2}$ released. The repeated addition $\times$ low fertility soil showed $133 \%$ more $\mathrm{CO}_{2}$ emission than medium fertility soil $\times$ control. The interaction of amended soils $\times$ time illustrated low fertility soil $\times 1$ st week of time (mean wise) released $506 \%$ more $\mathrm{CO}_{2}$ than medium fertility soil $\times 10$ th week of study period. The single $\times 2$ nd week of time emitted $1036 \%$, the highest $\mathrm{CO}_{2}$ over to control $\times 10$ th week of study period (Figure 2 ).

Similar trend of $\mathrm{CO}_{2}$ release was observed by glucose$\mathrm{C}$ additions (single and repeated) as observed in above mentioned $\mathrm{CO}_{2}$ release, when difference between additions and control values were calculated in amended soils. In repeated addition $\mathrm{CO}_{2}$ emission gradually increased with increase of time (Figure2 \& 3b).
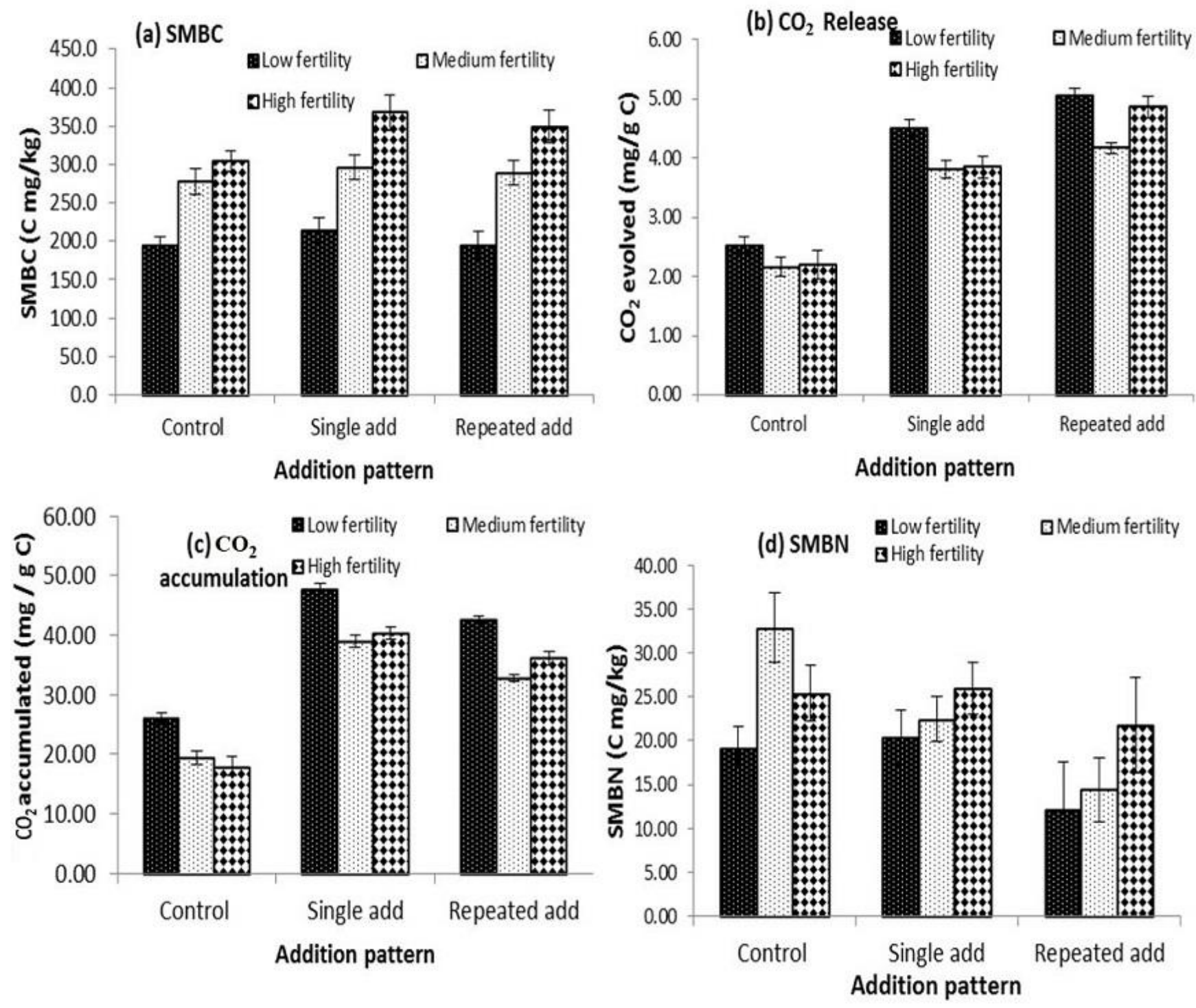

Figure 3: Mean values of parameters affected by different glucose-C additions in black soils during whole incubation period 


\section{Change in soil total carbon dioxide $\left(\mathrm{CO}_{2}\right)$ accumulation by glucose addition patterns}

The application of glucose- $\mathrm{C}$ as repeated addition illustrated the highest accumulation of $\mathrm{CO}_{2}\left(75.9 \mathrm{mg} \mathrm{g}^{-1} \mathrm{C}\right.$ soil), followed by single addition $\left(67.6 \mathrm{mg} \mathrm{g}^{-1} \mathrm{C}\right.$ soil) and control (38.0 $\mathrm{mg} \mathrm{g}^{-1} \mathrm{C}$ soil), during the $15^{\text {th }}$ week of incubation (Figure 4). The mean $\mathrm{CO}_{2}$ accumulation of all weeks illustrated the higher $\mathrm{CO}_{2}$ by single addition than repeated addition and control in all soils (Figure 3c).
The low fertility soil of single addition demonstrated $\mathrm{CO}_{2}$ accumulation of 22.4 and $17.6 \%$ higher than medium and high fertility soils respectively (Figure 3c). The highest average $\mathrm{CO}_{2}$ accumulation values were observed in $15^{\text {th }}$ and $14^{\text {th }}$ weeks of study period, which were $628 \%$ and $589 \%$ over the $1^{\text {st }}$ week (Figure 4). The positive interaction between amended soils and glucose-C additions was observed. The single addition $\times$ low fertility soil showed $163 \%$ more $\mathrm{CO}_{2}$ accumulation than Control $\times$ high fertility. (Figure $3 \mathrm{c}$ ). The interaction of repeated addition $\times 15^{\text {th }}$ week
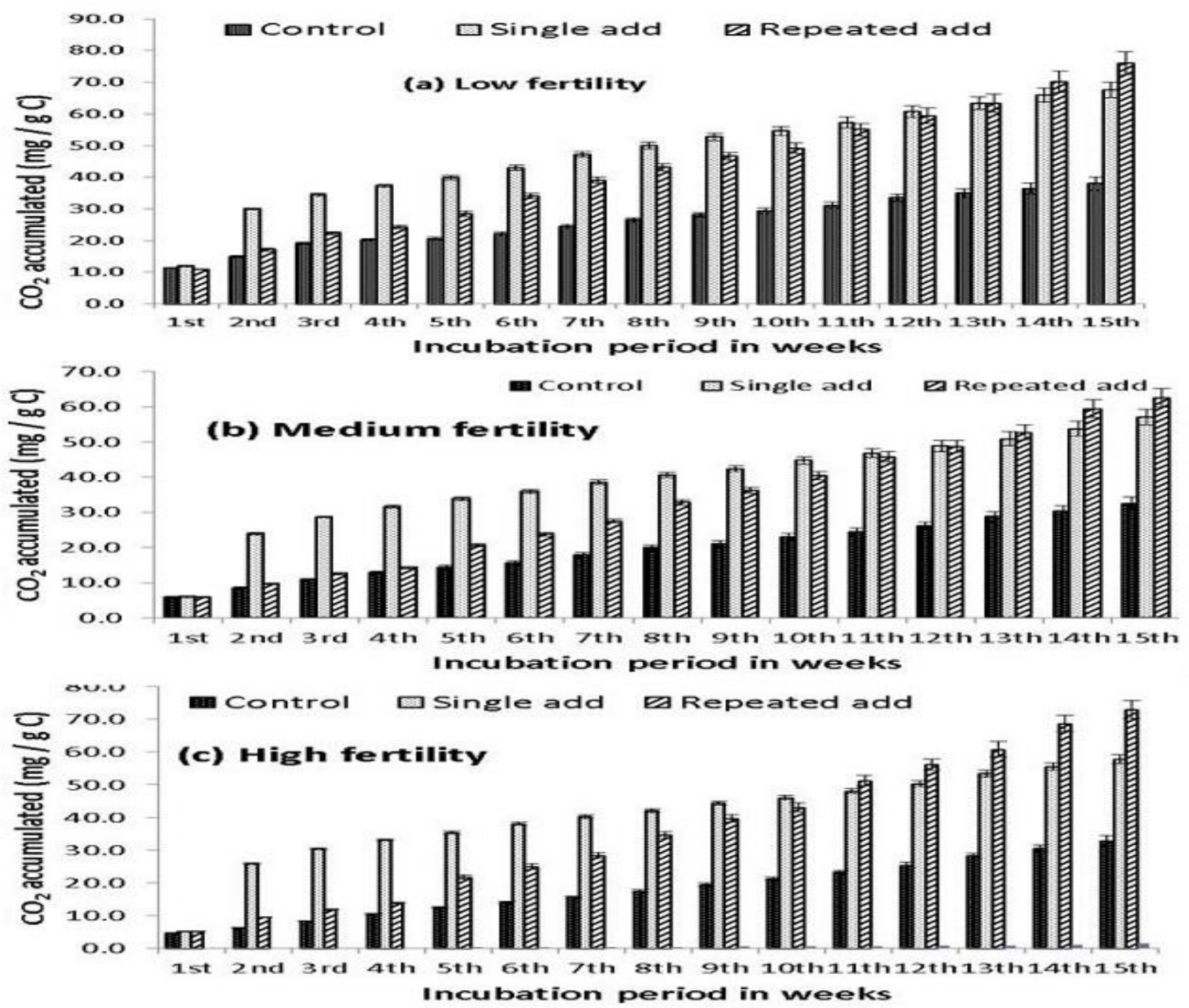

Tukey HSD < 0.05: Low fertility (Glucose add: 0.411, Weeks:1.32, Glucose add x weeks: 2.67): Medium fertility (Glucose add: 0.301, Weeks:0.975, Glucose add x weeks: 1.96): High fertility (Glucose add:0.324, Weeks:1.05, Glucose add x weeks: 2.11).

Figure 4: Total $\mathrm{CO}_{2}$ accumulation of black soils with different glucose-C additions at various interval periods 
showed $828 \%$ higher $\mathrm{CO}_{2}$ accumulation than repeated addition $\times 1^{\text {st }}$ week (Figure 4 ). The difference among single, repeated and control showed similar trend of $\mathrm{CO}_{2}$ accumulated as observed in above para of $\mathrm{CO}_{2}$ accumulation. The single addition consistently showed higher values of $\mathrm{CO}_{2}$ accumulation in all soils upto $10^{\text {th }}$ week of incubation period. After $11^{\text {th }}$ and $12^{\text {th }}$ weeks repeated addition, accumulated more $\mathrm{CO}_{2}$ than single addition. In repeated addition $\mathrm{CO}_{2}$ accumulation gradually increased with increase of time (Figure 4).

\section{Discussion}

The study was carried out to affirm the hypothesis that single addition may produce more microbial biomass carbon and $\mathrm{CO}_{2}$ in short period than repeated additions, because initially it contains large amount of substrate, while repeated addition will produce in larger period ranging from weeks to months. The findings of the study are discussed as under:

The glucose-C additions (single \& repeated additions) showed variable impact on SMBC. The observations of SMBC were recorded on $3^{\text {rd }}, 6^{\text {th }}, 9^{\text {th }}, 12^{\text {th }}$ and $15^{\text {th }}$ week of study, respectively. Single addition on an average basis produced more microbial biomass carbon than repeated additions during the $3^{\text {rd }}$ week of study period as expected according to hypothesis (Figure 1). The important driving force for microbial processes is soil carbon, especially for soil respiration and mineralization processes. Soil mineralization and respiration may be carried because of microbes which change quantity and availability of soil carbon (Jenkinson et al. 1985; Kuzyakov et al. 2000). Even though earlier findings have been illustrated that SMBC (soil microbial biomass carbon) can be triggered by little amounts of glucose-C (Nobili et al., 2001; Mondini et al., 2006). The single addition contributed more SMBC in initial incubation phase ( $3^{\text {rd }}$ week) due to availability of high substrate content; it decreased immediately in $6^{\text {th }}$ week due to high $\mathrm{C}$ demand by microbes or it may be the substrate pressure on soil biota. The continuous pressure on soil biology may check microbial biomass from achieving full recovery (Allison et al. 2008). The study further indicated that mineralization of glucose as single addition decreased with time. In contrast, repeated addition enhanced the glucose mineralization with time and ultimately contributed to microbial biomass. Similar findings were reported by Hamer and Marschner (2005), reported that repeated substrate increased mineralization with time.

In our study response of glucose as single and repeated additions with different fertility levels were used to maintain optimal microbial activity. The highest (90\%) SMBC was observed in bottles that contained the high fertility soil over the low fertility soil, similar findings were reported by
(Malik et al., 2013), who reported that organic amendments stimulated microbial community, mineral nutrition of plants. Soil microbes enhanced plant nutrition by encouraging availability of nutrients through microbial biomass.

Change in $\mathrm{CO}_{2}$ release is depending on amount of substrate addition (glucose or FYM). This study, single and repeated glucose- $\mathrm{C}$ additions were used to investigate the $\mathrm{CO}_{2}$ released from soil organic matter and microbial biomass. Single glucose $\mathrm{C}$ addition showed the highest $\mathrm{CO}_{2}$ over the repeated addition during $2^{\text {nd }}$ week of incubation (Figure 2). Single addition included the maximum glucose $\mathrm{C}$ addition at a time or in one application which reflected in the highest $\mathrm{CO}_{2}$ release. The results are in agreement with the findings of Conde et al. (2005) and Hamer and Marschner (2005) were reported that the decomposition of glucose $-\mathrm{C}$ (easily available $\mathrm{C}$ source) showed greater effects than the addition of manure (low available substrates) to soil. The quantity of more $\mathrm{CO}_{2}$ emission gave key clues regarding the sources (Nottingham et al., 2009; Blagodatskaya et al., 2010). The highest $\mathrm{CO}_{2}$ concentration was observed in $2^{\text {nd }}$ week of study period by single addition and it decreased subsequently in the rest of all weeks till the $15^{\text {th }}$ week of study. In contrast, repeated addition initially released very less amount of $\mathrm{CO}_{2}$ while it enhanced in later weeks of study period. Considering the cumulative $\mathrm{CO}_{2}$ release for 116 days of incubation study, $12.9 \%$ and $88.1 \%$ higher $\mathrm{CO}_{2}$ was released by single addition than repeated addition and control, respectively, in low fertility soil. (Figure 4). Similar trend in total cumulative $\mathrm{CO}_{2}$ release of whole incubation study illustrated as $\mathrm{CO}_{2}$ released in individual weeks. Glucose addition significantly enhanced the cumulative $\mathrm{CO}_{2}$ in comparison to control. Hammer and Marschner (2005) reported the triggering effects after substrate addition occurring during the intensive substrate decomposition. Single addition showed higher accumulation of $\mathrm{CO}_{2}$ than repeated addition. This would be because of small amount of glucose- $\mathrm{C}$ addition could not be enough to activate microbes and this could be resulted by depletion of microbial carbon or energy deficit, that leads activity of microbes and their nutrient demand (Cheng and Kuzyakov, 2005).

\section{Conclusion}

The findings of our study showed that scope of glucose additions on low, medium and high fertility soils. Single glucose-C addition in combination with different soil fertility levels augmented the microbial biomass and triggered $\mathrm{C}$ mineralization for shorter period (up to 3 weeks). The repeated addition of glucose in combination with different soil fertility levels also enhanced soil microbial biomass, $\mathrm{CO}_{2}$ release and $\mathrm{C}$ mineralization in longer incubation period. So, it can be suggested that 
repeated addition of glucose may be studied for longer incubation period and in more splits for better response of microorganisms and carbon mineralization. Moreover, our results suggest that activation of microbes with glucose addition in different soil fertility levels, addition patterns (single \& repeated) and localization of microorganisms to added glucose are key factors that control carbon mineralization.

\section{Acknowledgements}

This project is financially supported by National Science Foundation of China.

\section{References}

Allison, S.D. and H. Martiny. 2008. Resistance, resilience and redundancy in microbial communities. Proceedings of National Academy of Sciences U.S.A 105: 11512 11519.

Blagodatskaya, E., S. Blagodatsky, M. Dorodnikov and Y. Kuzyakov. 2010. Elevated atmospheric $\mathrm{CO}_{2}$ increases microbial growth rates in soil: results of three $\mathrm{CO}_{2}$ enrichment experiments. Global Change Biology 16: $836-848$.

Cheng, W. and Y. Kuzyakov 2005. Root effects on soil organic matter decomposition. p.119-143. In: Roots and Soil Management: Interactions Between Roots and the Soil. S. Wright, R. Zobel (eds.). Agronomy monograph No. 48. ASA, Madison.

Conde, E.M., M. Cardenas, P. Mendoza and L. Dendooven. 2005. The impacts of inorganic nitrogen application on mineralization of $\mathrm{C}$ labeled maize and glucose on priming effect in saline alkaline soil. Soil Biology and Biochemistry 37:681-691.

Docampo, R., P. Ulrich and S.N. Moreno. 2010. Evolution of acid ocalcisomes and their role in polyphosphate storage and osmo regulation in eukaryotic microbes. Philosophy Transactions of Royal Society 365: 775784.

Falkowski, P., R.J. Scholes, E. Boyle, J. Canadell, D. Canfield, J. Elser, N. Gruber, K. Hibbard, S. Linder, F.T Mackenzie, B. Moore, T. Pedersen, Y. Rosenthal, S. Seitzinger, V.Smetacek and W. Steffen. 2000. The global carbon cycle: a test of our knowledge of earth as a system. Science 290: 291-296.

Gichangi, E.M., P.N. Mnkeni and P.C. Brooks. 2009. Effects of goat manure and inorganic phosphate addition on soil inorganic and microbial biomass phosphorus fractions under laboratory incubation conditions. Soil Science and Plant Nutrition 55: 764771.
Hamer, U. and B. Marschner. 2005. Priming effects in different soil types induced by fructose, alanine, oxalic acid and catechol additions. Soil Biology and Biochemistry 37:445-454.

Jenkinson, D.S., R.H. Fox and J. H. Rayner.1985 Interactions between fertilizer nitrogen and soil nitrogen - the so-called 'priming' effect. Journal of Soil Science 36:425-444.

Khan, K.S. and R.G. Joergensen. 2009. Changes in microbial biomass and $\mathrm{P}$ fractions in biogenic household waste compost amended with inorganic $\mathrm{P}$ fertilizers. Bioresources Technology 100: 303-309.

Kristiansen, S.M., M. Brandt, E.M. Hansen, J. Magid and B.T. Christensen. 2004. ${ }^{13} \mathrm{C}$ signature of $\mathrm{CO}_{2}$ evolved from incubated maize residues and maize-derived sheep faeces. Soil Biology and Biochemistry 36: 99-105

Kuzyakov, Y., J.K. Friedel and K. Stahr. 2000 Review of mechanisms and quantification of priming effects. Soil Biology and Biochemistry 32: 1485-1498.

Malik, M.A., K.S. Khan, P. Marschner and Fayyaz-ulHassan. 2013. Microbial biomass, nutrient availability and nutrient uptake by wheat in two soils with organic amendments. Journal of Soil Science and Plant Nutrition 13 (4): 955-966.

Malik, M.A., K.S. Khan, P. Marschner and S. Ali. 2012. Organic amendments differ in their effect on microbial biomass and activity and on P pools in alkaline soils. Biology and Fertility of Soils 49(4): 415-425. doi:10.1007/s00374-012-0738-6.

Mondini, C., M.L. Cayuela, M.A. Sanchez-Monedero, A. Roig and P.C. Brookes. 2006. Soil microbial biomass activation by trace amounts of readily available substrate. Biology and Fertility of Soils 42: 542 -549.

Moritsuka, N., J. Yanai, K. Mori and T. Kosaki. 2004. Biotic and abiotic processes of nitrogen immobilization in the soil-residue interface. Soil Biology and Biochemistry 36: 1141-1148. doi: 10.1016/j.soilbio.2004.02.024.

Nannipieri, P., L. Giagnoni, G. Renella, E. Puglisi, B. Ceccanti, G. Masciandaro, F. Fornasier, M.C. Moscatelli and S. Marinari. 2012. Soil enzymology: classical and molecular approaches. Biology and Fertility of Soils 48: 743-762. doi:10.1007/s00374-0120723.

Nobili, D., M. Mondini and C. Brookes. 2001. Soil microbial biomass is triggered into activity by trace amounts of substrate. Soil Biology and Biochemistry 33: 1163-1170.

Nottingham, A.T., H. Griffiths, P.M. Chamberlain, A.W. Stott and E.V. Tanner. 2009. Soil priming by sugar and leaf-litter substrates: a link to microbial groups. Applied Soil Ecology 42: 183-190. 
Ryazanova, L.P., N.E. Suzina, T.V. Kulakovskaya and I.S. Kulaev. 2009. Phosphate accumulation of Acetobacter xylinum. Archea Microbiology 191: 467-471.

Saccone, P., S. Morin, F. Baptist, J.M. Bonneville, M.P. Colace, F. Domine, M. Faure, R. Geremia, J. Lochet, F. Poly, S. Lavorel and J.C. Clément. 2013. The effects of snowpack properties and plant strategies on litter decomposition during winter. Journal of Plant and Soil 363: 215-229. doi:10.1007/s11104-012-1307-3
Thomas, R.J. and N.M. Asakawa. 1993. Decomposition of leaf litter from tropical forage grasses and legumes. Soil Biology and Biochemistry 25: 1351-1361. doi:10.1016/0038-0717 (93)90050.

Vance, E.D., P.C. Brookes and D.S. Jenkinson. 1987. An extraction method for measuring soil microbial biomass Carbon. Soil Biology and Biochemistry 19: 703-707. 